\title{
Pars Plana Vitrectomy with Internal Limiting Membrane Peeling in Patients with Myopic Foveoschisis
}

\author{
Kemal Yuksel ${ }^{l}$, Onur Olcucu², Alperen Koc ${ }^{l}$, Mesut Togac ${ }^{1}$, Cengiz Alagoz ${ }^{1}$, Ahmet Taylan Yazici ${ }^{1}$
}

\begin{abstract}
Objective: To report the clinical and surgical outcomes of patients with myopic foveoschisis (MF).

Methods: Thirteen eyes in ten symptomatic MF patients who underwent pars plana vitrectomy (PPV) and gas tamponade with internal limiting membrane (ILM) peeling were retrospectively identified. Best corrected visual acuity (BCVA) and central foveal thickness (CFT) were assessed preoperatively and six months postoperatively. Complications during and after surgery were also recorded.

Results: The median BCVA significantly improved from 20/160 to 20/100 ( $p=0.03)$. In subgroup analysis, eight eyes (61\%) demonstrated significant BCVA improvements from 20/80 to 20/50 ( $<0.001)$, whereas five eyes had similar BCVA with preoperative level after six months of surgery $(p=0.32)$. The mean CFT decreased from 526 microns at baseline to 214 microns at six months of surgery $(p<0.001)$. Optical coherence tomography scans revealed a complete MF resolution in ten eyes (76\%) and a partial MF resolution in three eyes. Peripheral retinal tear was developed in one patient during surgery and one patient had cataract after surgery, those were treated accordingly.
\end{abstract}

Conclusion: PPV with ILM peeling followed by gas tamponade is a safe and effective procedure for the treatment of eyes with myopic foveoschisis. Larger studies with longer follow-ups will further establish the efficacy and safety of this procedure. J Clin Exp Invest 2016; 7 (2): 139-143

Key words: Myopic foveoschisis; retinoschisis; macular hole; internal limiting membrane.

\section{Myopik foveoskizisi olan hastalarda pars plana vitrektomi ve internal limitan membran soyulmast}

\section{ÖZET}

Amaç: Miyopik foveoskizi (MF) olan hastalarda klinik ve cerrahi sonuçları bildirmektir.

Yöntemler: Pars plana vitrektomi, gaz tamponadı ve internal limitan membran (ILM) soyulması yapılmış semptomatik 10 MF hastasının 13 gözü geriye dönük olarak incelendi. En iyi düzeltilmiş görme keskinliği (ElDGK) ve merkezi fovea kalınlığı (MFK) ameliyat öncesi ve sonrasındaki 6 ayda ölçüldü. Cerrahi sırasında ve sonrasında gerçekleşen komplikasyonlar ayrıca kaydedildi.

Bulgular: Ortalama EIDGK belirgin bir şekilde artarak 20/160'dan 20/100'e yükseldi $(p=0,03)$. Altgruplar incelendiğinde 8 (\%61) hastanın EIDGK belirgin bir şekilde artarak 20/80'den 20/50'ye yükselirken $(p<0,001) 5$ gözde operasyon öncesi ve sonrası EiDGK'de belirgin bir değişim görülmedi $(p=0,32)$. Ortalama MFK 536 mikrondan ameliyat sonrası altıncı ayda 214 mikrona geriledi $(p<0,001)$. Optik koherans tomografiside $10(76 \%)$ gözde MF' nin tam, 3 gözde kismi olarak yatışığı görüldü. Ameriyat sırasında bir hastada peripheral retinal yırtık, ameliyat sonrası takiplerde bir hastada katarakt gelişti ve bunlar uygun bir şekilde tedavi edildi.

Sonuçlar: ILM soyulması ile birlikte yapılan PPV ve gaz taponadı uygulaması MF'si olan gözlerde etkin ve güvenilirdir. Daha çok hasta katılımının olduğu daha uzun süre takipli çalışmalar ileride bu işlemin etkinlik ve güvenilirliğini daha güvenilir bir şekilde ortaya koyacaktır.

Anahtar kelimeler: Miyopik foveoskizis, retinoskizis, makülar hol, internal limitan membran.

${ }^{1}$ Beyoglu Eye Training and Research Hospital, Istanbul, Turkey

${ }^{2}$ Kirklareli Government Hospital, Kirklareli, Turkey

Correspondence: Kemal Yuksel,

Bereketzade Mah. Bereketzade Cami Sok. No: 157, Beyoglu, 34420, Istanbul, Turkey Email: drkemal68@gmail.com

Received: 11.04.2016, Accepted: 27.04.2016

Copyright (C) JCEI / Journal of Clinical and Experimental Investigations 2016, All rights reserved 


\section{INTRODUCTION}

Pathological myopia may affect central vision by many mechanisms. Macular retinoschisis in highly myopic eyes, also known as myopic foveoschisis (MF) is one of the major causes of central visual loss [1]. Although myopic foveal retinoschisis was first introduced as the splitting of the inner retinal layers at the macula in high myopic patients by Takano and Kishi before the advent of the optical coherence tomography (OCT), $\mathrm{MF}$ is increasingly being well recognized by means of OCT $[2,3]$.

The patients with MF may be asymptomatic in the time of the diagnosis, but previous studies documented the slowly progressive course of the disease leading to severe central visual loss in untreated cases. Symptoms from MF were ranging from slightly metamorphopsia to marked visual impairment which could be also related to macular hole formation [4]. Surgical intervention is preferred for MP patients who had symptoms of visual decline, metamorphopsia, no major atrophic changes on OCT and whose visual acuity is $20 / 40$ or worse [5].

The previous studies demonstrated fairly successful surgical results in treating and preventing the progression of an MF. However, best surgical procedure is still a debate at present. Although posterior buckling with or without Ando plombe has been describe in a few studies, the majority of the studies focused on PPV and gas tamponade with or without ILM peeling [5-8]. The purpose of this current study is to evaluate visual and surgical outcomes of PPV and internal limiting membrane (ILM) peeling followed by gas tamponade for patients with MF.

\section{METHODS}

This retrospective study was approved by the ethics committee of the Beyoglu Training and Research Hospital. The medical records of all MF patients requiring surgery in our hospital were retrospectively reviewed. Oral and written informed consents were obtained from all of the patients. Patients who had at least six months follow up were included in this study. Participants were excluded from the study if they aged less than 18 years or had myopia less than -6 diopters, macular hole or epiretinal membrane documented on OCT. The study conformed to the tenets of the ethical standards of 2013 Declaration of Helsinki.

The collected data included patient gender, age, past ocular history, lens status, pre- and postoperative best corrected visual acuity (BCVA) and central foveal thickness (CFT) measured by OCT. The foveal central thickness was measured by means of the retinal thickness mode in the OCT software (Heidelberg Engineering, Heidelberg, Germany, Spectralis software version 5.1.1.0, Eye Explorer Software 1.6.1.0). Main outcome measurements were BCVA and CFT. All intraand postoperative complications were also recorded.

The decision for surgery was given by the patient treating physician according to visual acuity decrease and other visual symptoms due to myopic macular disease. All patients underwent standard three port 23 gauge PPV. Simultaneous phacoemulsification was performed on eyes with a cataract. The posterior vitreous detachment (PVD) was confirmed by using active aspiration and created in eyes without a PVD. Any visible vitreous was cut and removed with the assistance of an intravitreal injection of triamcinolone acetonide during the surgery. All patients required to ILM staining by using brilliant blue during surgery and ILM was peeled in a curviliniear fashion from the retina. Special attendance was paid to prevent a macular hole occurrence during ILM peeling. After the fluid-air exchange, \%10 perfluoropropane (C3F8) was used for the retinal tamponade. All of the patients were instructed to maintain a prone posture for one week after surgery.

Data analyses were performed using SPSS version 21.0 (IBM, Armonk, NY, USA) for Windows. Normality of all of the data samples was assessed using the Shapiro-Wilk test. The mean change in BCVA was compared using non-parametric Wilcoxon signed rank test. Snellen visual acuities were converted to $\operatorname{logMAR}$ prior to statistical analysis and then converted Snellen equivalents for reporting purpose. Two tailed $t$ test was used to analyze the mean change in height of central foveal thickness (CFT). Unless otherwise indicated, the results are expressed as mean \pm standard deviation and $p$ value less than 0.05 was considered statistically significant.

\section{RESULTS}

A total of thirteen eyes in ten patients with MF were recruited in this study. Myopic foveoschisis was bilateral in three patients. The clinical characteristics of patient with MF were summarized in Table 1.

All patients predominantly referred to the retina department with complain of marked visual decrease in recently. Three patients (33\%) were also suffering metamorphopsia before surgery. Pars plana vitrectomy combined with phacoemulsification and a pos- 
terior chamber intraocular lens implantation was performed in four eyes $(30 \%)$. Three eyes required creating a PVD by active aspiration and in the other eyes; a large posterior liquefied cavity was present. As an intraoperative complication, a peripheral retinal tear was observed and immediately surrounded with 3 rows of argon laser photocoagulation during vitrectomy.

Ten eyes $(76 \%)$ of nine patients had a complete MF resolution with a complete foveal reattachment on OCT scans after surgery. Figure 1 shows preoperative and postoperative OCT scans of a case (Case 7) which had a complete MF resolution with a complete foveal reattachment. In other three (24\%) eyes, a complete reattachment of MF was obtained, but a small subfoveal or parafoveal detachment persisted postoperatively. A case (Case 4) with partial foveal reattachment was depicted in Figure 2. The mean CFT decreased from 526 microns preoperatively to 214 microns six months postoperatively (Wilcoxon signed rank test, $\mathrm{p}<0.001$ ).

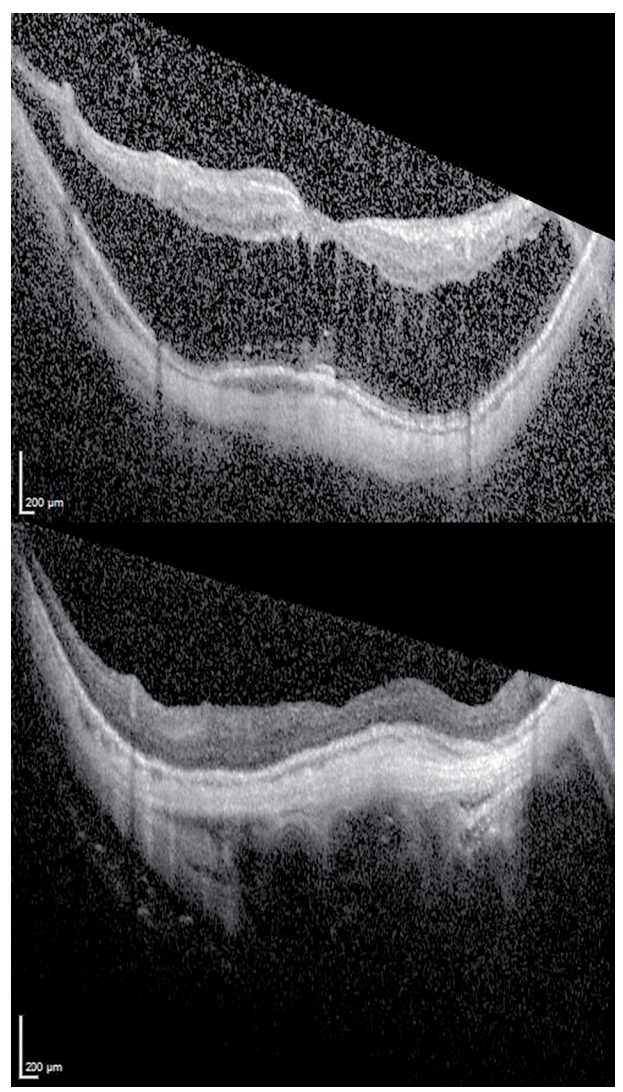

Figure 1. Optical coherence tomography of Case 7. Macular optical coherence tomography scan of the patient revealed extensive retinoschisis with foveal detachment (top). There was complete reattachment of the fovea and resolution of the macular retinoschisis following vitrectomy with ILM peeling and C3F8 gas injection (bottom).
Table 1. Clinical characteristics of patients with myopic foveoschisis.

\begin{tabular}{lc}
\hline Characteristics & Value (Mean \pm SD) \\
\hline Age (years) & $49.84 \pm 10.82$ \\
Gender (M/F) & $3 / 7$ \\
Eye affected (R/L) & $6 / 7$ \\
Refractive error (D) & $-15.17 \pm 3.52$ \\
Axial length (mm) & $30.51 \pm 1.44$ \\
Lens status (eyes) & 11 \\
\hline \multicolumn{1}{c}{ Phakic } & 2 \\
$\quad$ Pseudophakic & 13 \\
Posterior staphyloma & 10 \\
Presence of PVD (eyes) & $11.46 \pm 4.33$ \\
Follow up (months) & 8.43 \\
\hline Duration of symptoms (months) &
\end{tabular}

SD: Standard deviation, M: Male, F: Female, R: Right, L: Left, D: Diopter, PVD: Posterior vitreous detachment

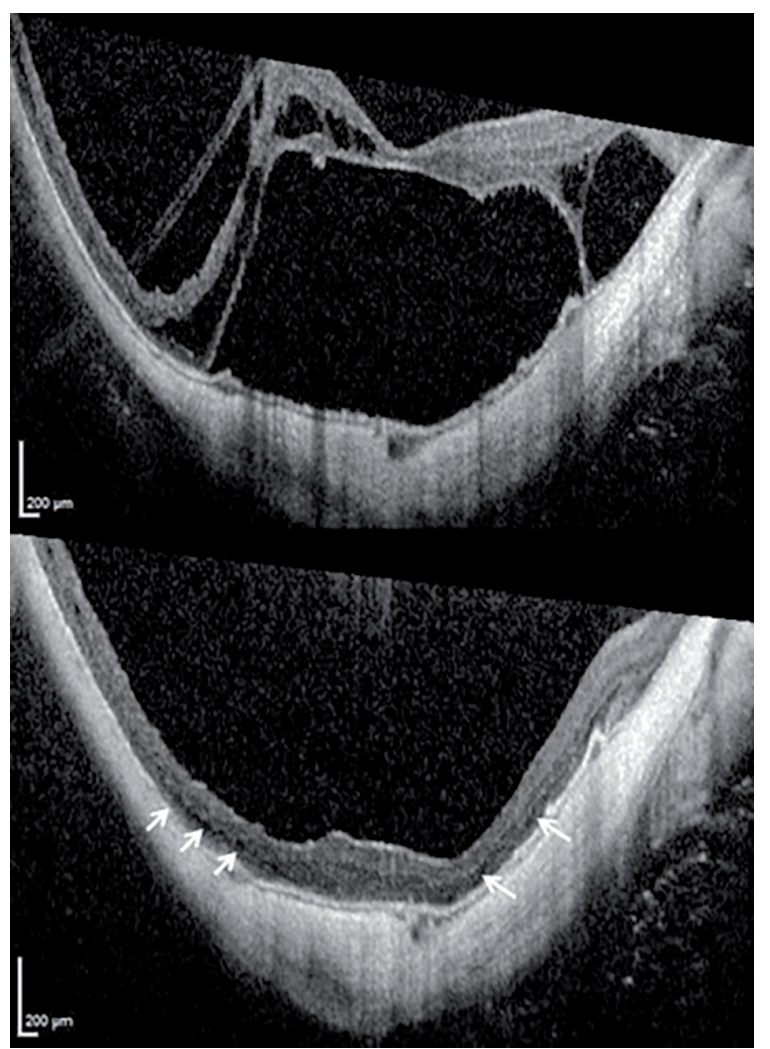

Figure 2. Optical coherence tomography of Case 4. Preoperative optical coherence tomography scan of the macula demonstrated extensive macular retinoschisis with foveal detachment (top). Postoperatively, complete reattachment of the macular retinoschisis was achieved, but small subfoveal and parafoveal detachments (white arrows) persisted (bottom). 
All patients had symptomatic improvement in visual symptoms after surgery. The median BCVA significantly improved from 20/160 to 20/100 (Wilcoxon signed rank test, $\mathrm{p}=0.03$ ). Best corrected visual acuity improved from $20 / 80$ to $20 / 50$ (two-tailed t test, $p<0.001)$ in eight $(61 \%)$ eyes of thirteen eyes those also had a complete foveal reattachment after surgery. In other five eyes $(39 \%)$, the BCVA did not differ significantly after six months of surgery (two-tailed t test, $\mathrm{p}=0.32$ ).

A patient (Case 9) admitted to the clinic with a complaint of gradual deterioration of her vision after five months of surgery. Examination revealed a visually significant cataract, resulting in decrease of her BCVA from 20/60 to 20/100. An uneventful cataract surgery was performed and her BCVA improved to $20 / 60$.

\section{DISCUSSION}

Several studies demonstrated that MF is a relatively common complication in highly myopic eyes with a slowly progressive course. Although the patients with MF can preserve their vision for many years, increased stretching and distortion of macula can lead to a foveal retinal detachment or macular hole development, thereby resulting in several visual impairment [4]. The pathogenesis of the disease is still speculative, the tractional forces caused by premacular vitreous cortex seem to play essential role of the development of MF. Another proposed mechanism of the MF pathogenesis is the relative resistance of the inner retinal layers and the retinal vessels to outward traction caused by a progressive ectasia of the sclera in highly myopic eyes [9, 10]. Consistent with this hypothesis, a study reported the presence of retinoschisis on OCT in patients with high myopia greater than 8 dioptre only in the group with posterior staphyloma [11].

Several studies have been conducted to demonstrate the efficacy of PPV with ILM peeling and gas tamponade in treating symptomatic patients with MF $[5,6,11,12]$. In our case series, the mean BCVA improved from $20 / 80$ to $20 / 50$ after six months of surgery. Chang et al reported that the visual improvement was statistically significant from $20 / 130$ to $20 / 70$ in a retrospective study which has similar design with our study [13]. The visual gains are similar after surgery in both studies however, this study also includes the results of MF patients with macular hole, and thus the scores of preoperative and postoperative BCVA are lower than our study.
Ten eyes (76\%) attained a complete MF resolution with a complete foveal reattachment postoperatively in this study. Similar to our result, Fang et al reported a complete reattachment of fovea in $67 \%$ of eyes and a parafoveal detachment in $33 \%$ of eyes in patients with MF following vitrectomy and gas tamponade [14]. However, only eight (61\%) eyes gained one or more Snellen lines in BCVA and had a significant visual improvement in our study. The best corrected visual acuity did not differ in two eyes with a complete foveal reattachment and in three eyes with a partial foveal reattachment. The lack of visual improvement in eyes with partial foveal reattachment can be attributed to disruption of the retinal layers in the foveal region. Other two eyes had a long interval between the foveal detachment and the surgery therefore; the lack of improvement can be associated with the atrophic changes in macula. Findings in the present study are consistent with the findings of Ikuno et al who conducted a study concerning the relationship between postoperative foveal status and surgical results in MF following PPV with ILM peeling and gas tamponade [5]. This study revealed the negative correlation between the symptom duration and visual improvement in eyes with MF following PPV with ILM peeling and gas tamponade.

The criteria for the surgical intervention in patients with MF were progressive visual symptoms, metamorphopsia, and reduction in visual acuity in this study. All patients were also examined by using new generation spectral-domain OCT. Preoperatively, OCT scans disclosed a marked increase in the thickness of the retina in the posterior pole area in all 13 eyes. As expected, the CFT was significantly reduced in all eyes postoperatively and this finding is also consistent with the previously published results $[5,6,11,12,13]$.

Internal limitan membrane peeling during PPV for MF is still a debate in vitreoretinal surgery. Some surgeons advocate ILM peeling to spare the area over the fovea from the anteriorly directed force caused by relatively shortened inner retina and ILM [11-18]. However, ILM peeling is challenging in patients with MF when the retinal thinning at macula and long axial length considered. This may predispose complications like iatrogenic macular hole development after surgery. Therefore, other surgeons prefer PPV without ILM peeling followed by gas tamponade for treating symptomatic patients with MF. Likewise, favorable visual and anatomical results were reported in the previously published studies concerning vitrectomy without ILM removal and gas tamponade in the treatment 
of MF [19-20]. We did not detect MH development in eyes of this study following vitrectomy, the complications we encountered in intra- and postoperative were relatively common and easily managed.

The retrospective design is a major drawback for this study. The other limitations to the study include the small number of subjects in the groups and a short follow up time period. Patients with this condition are relatively uncommon, rendering it difficult to have large numbers of study eyes with long follow-up.

In summary, vitrectomy and gas tamponade with ILM peeling appears to have favorable visual and anatomical results for treating patients with MF. Further follow up in larger patient cohort required to ascertain the ability of this surgery to achieve long term stabilization of fovea in eyes with MF.

Declaration of Conflicting Interests: The authors declare that they have no conflict of interest.

Financial Disclosure: No financial support was received.

\section{REFERENCES}

1. Benhamou N, Massin P, Haouchine B, et al. Macular retinoschisis in highly myopic eyes. Am J Ophthalmol. 2002;133:794-800.

2. Takano M, Kishi S. Foveal retinoschisis and retinal detachment in severely myopic eyes with posterior staphyloma. Am J Ophthalmol. 1999;128:472-6.

3. Panozzo G, Mercanti A. Optical coherence tomography findings in myopic traction maculopathy. Arch Ophthalmol. 2004;122:1455-60.

4. Shimada N, Ohno-Matsui K, Baba T, et al. Natural course of macular retinoschisis in highly myopic eyes without macular hole or retinal detachment. Am J Ophthalmol. 2006; 142: 497-500.

5. Ikuno Y, Sayanagi K, Soga K, et al. Foveal anatomical status and surgical results in vitrectomy for myopic foveoschisis. Jpn J Ophthalmol. 2008;52:269-76.

6. Kobayashi H, Kishi S. Vitreous surgery for highly myopic eyes with foveal detachment and retinoschisis. Ophthalmology 2003;110:1702-7.
7. Mateo C, Burés-Jelstrup A, Navarro R, Corcóstegui B. Macular buckling for eyes with myopic foveoschisis secondary to posterior staphyloma. Retina. 2012;32:1121-8.

8. Ji X, Wang J, Zhang J, et al. The effect of posterior scleral reinforcement for high myopia macular splitting. J Int Med Res. 2011;39:662-6.

9. Tang J, Rivers MB, Moshfeghi AA, et al. Pathology of macular foveoschisis associated with degenerative myopia. J Ophthalmol. 2010;55:10-6.

10. Ikuno Y, Gomi F, Tano Y. Potent retinal arteriolar traction as a possible cause of myopic foveoschisis. Am J Ophthalmol. 2005;139:462-7.

11. Baba T, Ohno-Matsui K, Futagami S, et al. Prevalence and characteristics of foveal retinal detachment without macular hole in high myopia. Am J Ophthalmol. 2003;135:33842.

12. Ikuno Y, Sayanagi K, Ohji M, et al. Vitrectomy and internal limiting membrane peeling for myopic foveoschisis. Am J Ophthalmol. 2004;137:719-24.

13. Chang JS, Flynn HW Jr, Engelbert M, et al. Pars plana vitrectomy in patients with myopic macular retinoschisis. Br J Ophthalmol. 2014;98:534-7.

14. Fang X, Weng Y, Xu S, et al. Optical coherence tomographic characteristics and surgical outcome of eyes with myopic foveoschisis. Eye (Lond). 2009;23:1336-42.

15. Kuhn F. Internal limiting membrane removal for macular detachment in highly myopic eyes. Am J Ophthalmol. 2003;135:547-9.

16. Kanda S, Uemura A, Sakamoto Y, Kita H. Vitrectomy with internal limiting membrane peeling for macular retinoschisis and retinal detachment without macular hole in highly myopic eyes. Am J Ophthalmol. 2003;136:177-80.

17. Sayanagi K, Ikuno Y, Tano Y. Reoperation for persistent myopic foveoschisis after primary vitrectomy. Am J Ophthalmol. 2006;141:414-7.

18. Shimada N, Sugamoto Y, Ogawa M, et al. Fovea-sparing internal limiting membrane peeling for myopic traction maculopathy. Am J Ophthalmol. 2012;154:693-701.

19. Ho TC, Chen MS, Huang JS, et al. Foveola nonpeeling technique in internal limiting membrane peeling of myopic foveoschisis surgery. Retina. 2012;32:631-4.

20. Kwok AK, Lai TY, Yip WW. Vitrectomy and gas tamponade without internal limiting membrane peeling for myopic foveoschisis. Br J Ophthalmol. 2005;89:1180-3. 